\title{
Evidence for Vertical Partitioning of Strike-Slip and Compressional Tectonics from Seismicity, Focal Mechanisms, and Stress Drops in the East Los Angeles Basin Area, California
}

\author{
by Wenzheng Yang and Egill Hauksson
}

\begin{abstract}
We have synthesized the characteristics of the seismogenic zone in the east Los Angeles basin by analyzing earthquake data recorded during the past 30 years (1981-2010). The seismicity is distributed along the Whittier fault, with the majority of earthquakes located adjacent to the south side, in the depth range from 0 to $9 \mathrm{~km}$, with $b$ value of $1.1 \pm 0.05$ and mostly normal and strike-slip faulting. Within the depth range of $9-12 \mathrm{~km}$, the seismicity is scattered uniformly across the region, the $b$ value is $1.0 \pm 0.05$, and all three faulting styles are present. At the deepest depths $(12-18 \mathrm{~km})$, seismicity is sparse and primarily limited to a few clusters striking north; these deeper earthquakes primarily have reverse fault motion, and the $b$ value is $0.78 \pm 0.04$. Inversion of high-quality focal-mechanism data for the orientation of the regional stress field showed that the direction of maximum compressional stress rotates from $\mathrm{N} 12^{\circ} \mathrm{W}$ at shallow depth to due north at the bottom of the seismogenic zone. Similarly, a depth dependence is observed in stress drops calculated from $P$-wave source spectra, which indicate stress drop generally increases from $\sim 7 \mathrm{MPa}$ at shallow depth $(3 \mathrm{~km})$ to $\sim 53 \mathrm{MPa}$ at the base of the seismogenic zone $(17 \mathrm{~km})$. Overall, our results provide new evidence for the vertical partitioning of styles of deformation and state of stress within this complex fault system in the east Los Angeles basin.
\end{abstract}

Online Material: Stress drop fits to source spectra.

\section{Introduction}

Long-term regional seismicity is associated with ongoing tectonic movement in the seismogenic zone. From the analysis of earthquake source parameters and seismicity, we infer important physical features of the regional tectonic process and thereby improve our understanding of regional seismic hazards. Individual earthquake source properties, such as focal mechanisms and stress drops, are calculated from seismograms. From analyzing groups of earthquakes, we can infer temporal and spatial variations of earthquake source properties and thereby the evolution of the regional stress field. The long record of background seismicity in the Los Angeles area provides one of the best in situ information sources about the ongoing tectonic deformation.

The east Los Angeles (ELA) basin (Fig. 1) is a transition zone between the convergent tectonics of the Transverse Ranges and the right-lateral strike-slip tectonics of the Peninsular Ranges (e.g., Hauksson, 1990). In the ELA basin, the Whittier fault is the longest mapped fault, with a surface trace along the whole length (around $40 \mathrm{~km}$ ), striking to the north- west. Over the past 30 years, two moderate-size earthquakes occurred inside the ELA basin close to the Whittier fault: the 1 October 1987 Whittier Narrows $M_{\mathrm{L}} 5.9$ and the 29 July 2008 Chino Hills $M_{\mathrm{w}} 5.4$ earthquakes (e.g., Hauksson et al., 1988, 2008; Hauksson and Jones, 1989). The focal mechanisms exhibited reverse faulting for the Whittier Narrows mainshock and oblique faulting for the Chino Hills mainshock. A seismic reflection survey confirmed the existence of the Puente Hills blind-thrust fault system (Shaw and Shearer, 1999) to the south of the Whittier fault. One of the nodal planes in the Whittier Narrows mainshock focal mechanism was aligned with this blind thrust. To provide a detailed tectonic model of the region, we synthesize how the Whittier fault and the blind-thrust faults accommodate shortening across the region.

In this study, using earthquake data in the ELA basin over a period of the past 30 years, we systematically synthesized seismicity, focal mechanisms, stress-field orientation, and stress drops and inferred the regional seismotectonic characteristics. 


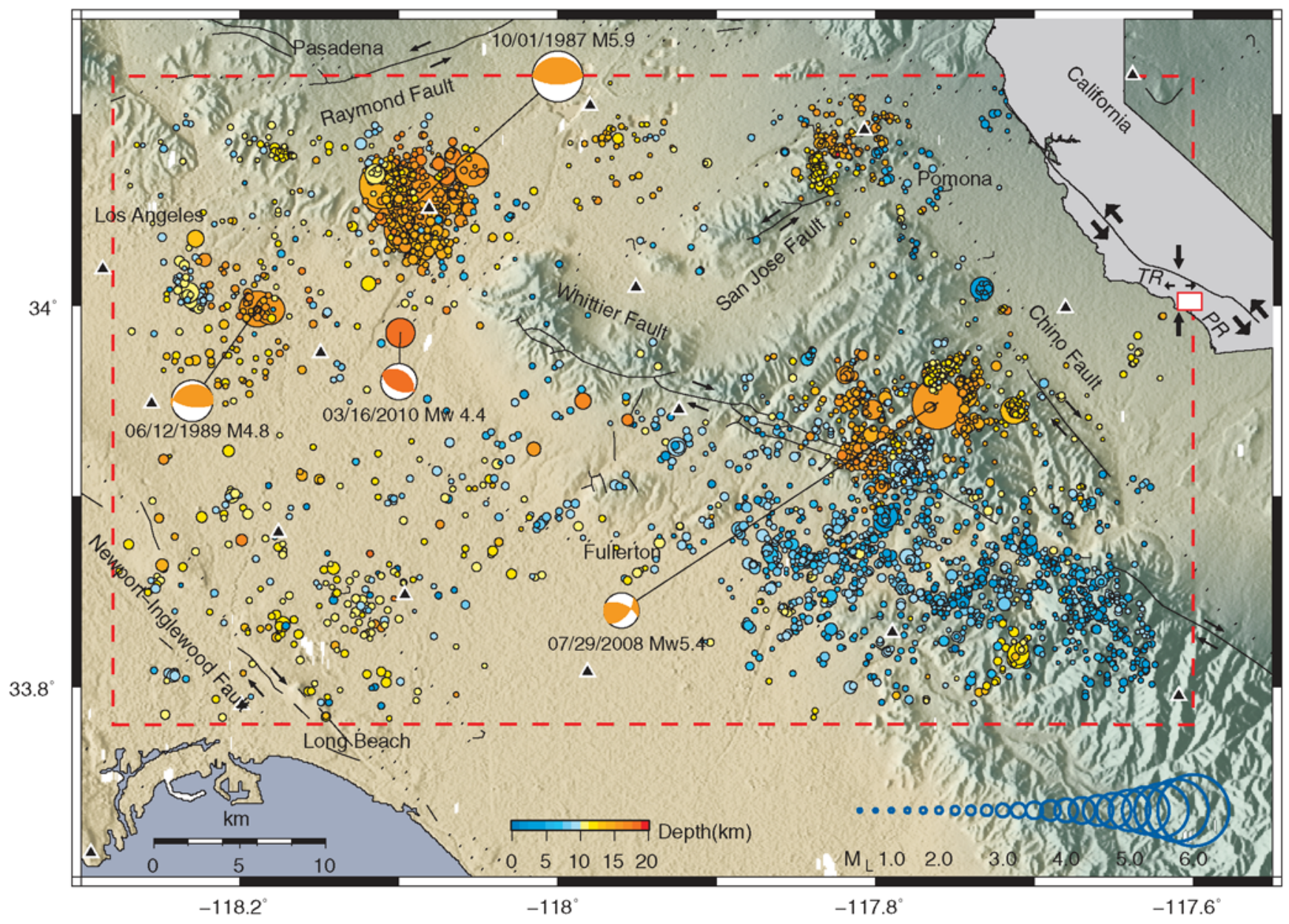

Figure 1. A data set of 3457 hypoDD relocated earthquakes (colored with depth and scaled with magnitude, with legends at the bottom) in the east Los Angeles (ELA) basin area (red dashed box) from 1 January 1981 to 16 March 2010. The 1987 Whittier Narrows $M_{\mathrm{L}} 5.9$ earthquake, 1989 Montebello $M_{\mathrm{L}}$ 4.8, 2008 Chino Hills $M_{\mathrm{w}} 5.4$ earthquake, and the 2010 Pico Rivera $M_{\mathrm{w}} 4.4$ earthquake are marked with focal mechanisms. Seismic stations are shown as triangles. The surface traces of major faults are in black, with fault motion marked by arrows. The insert (top right) shows the location of the ELA basin area (red rectangle) inside the state of California, in which the San Andreas fault (black curve) separates the North American plate and the Pacific plate, with relative plate motions marked with arrows. The Transverse Ranges (TR) are marked with north-south thrust and east-west escape tectonics, and the Peninsular Ranges (PR) are marked with strike-slip motion.

\section{Data}

We selected a rectangular area $\left(118.276^{\circ} \mathrm{W}\right.$ to $117.604^{\circ}$ $\mathrm{W} ; 33.784^{\circ} \mathrm{N}$ to $34.116^{\circ} \mathrm{N}$ ) (dashed red box in Fig. 1), as the ELA basin study area, where the seismicity is well recorded by the Southern California Seismic Network (SCSN; Hutton et al., 2010). From 1 January 1981 to 16 March 2010, 3828 events with magnitudes between 0.0 and 5.9 were recorded by the SCSN inside the study area. The past 30 years of seismicity include the $1987 M_{\mathrm{L}} 5.9$ Whittier Narrows and the $2008 M_{\mathrm{w}} 5.4$ Chino Hills earthquake sequences, as well as background earthquakes in the vicinity of the Whittier fault.

\section{Methods}

We relocated the seismicity using a three-dimensional (3D) velocity model determined with SIMULPS (Thurber,
1993; Hauksson, 2000). We derived differential travel times from the picks provided by the SCSN and applied hypoDD (Waldhauser and Ellsworth, 2000) to refine the hypocenters. We obtained 3457 relocated hypocenters ( $90 \%$ of the number of original events), with average relative location errors of less than $100 \mathrm{~m}$.

We calculated focal mechanism for the relocated earthquakes using the HASH method (Hardebeck and Shearer, 2002, 2003), which uses polarities of $P$-wave first motions and $S / P$ amplitude ratios. For the $P$-wave first motions, we used the event phase picks and corrected for reversed polarities. To calculate $S / P$ amplitude ratios, we analyzed 100 -samples/second waveforms recorded at stations with broadband three-component (HHE/HHN/HHZ) seismometers. We converted the waveforms from velocity to displacement and band-pass filtered them in the frequency range of $1-10 \mathrm{~Hz}$, which is consistent with other studies 
(e.g. Shearer, 1997). For each component, we calculated the absolute maximum amplitude in the first 2-s phase window for the $P$ and $S$ waves and in a 2 -s waveform window ahead of the $P$ arrival for background noise. For each station, the pre-event noise and the $P$-wave and $S$-wave amplitudes were calculated as the vector summations of amplitudes from all three components. Only records with a $P$-to-noise ratio above 3.0 were used in the focal mechanism calculation.

There are several methods for inverting focal mechanisms data to calculate the regional stress field (e.g., Angelier, 1984; Michael, 1984; Gephart and Forsyth, 1984; Hardebeck and Michael, 2006). In this study, we inverted for the principal stresses using the spatial and temporal stress inversion (SATSI) method (Hardebeck and Michael, 2006). The SATSI method is a damped grid-search inversion for stress tensor orientation. The damping helps to decrease the artificial noise or isolated data singularities associated with stressfield orientation inversion (Hardebeck and Michael, 2006).

Earthquake stress drop is the change in static stress from before to after the occurrence of an earthquake and is estimated from seismic waveforms. To calculate stress drops, we used vertical component (EHZ or HHZ) seismograms. We required that each event be recorded by at least three stations. We computed stress drop using displacement waveform (i.e., converted from velocity) and unified the sampling rates to be $100 \mathrm{~Hz}$. We calculated the spectra using a multitaper method (Thomson 1982; Park et al. 1987), with four taper windows. The waveform inside a -0.28 to 1.00 -s window relative to the $P$ arrival is selected for the spectrum calculation. We also calculated a noise spectrum using a waveform snippet just prior to the $P$ arrival, which has the same duration of $-0.28-1.00 \mathrm{~s}$. We required the spectra signal-to-noise ratio to be larger than 3.0 in a 2.35 to $30-\mathrm{Hz}$ frequency bandwidth. For each event and its 100 neighbors, we separated seismic source, station, and travel-time spectra from observed spectra using the method developed by Shearer et al. (2006). The detailed procedures were also documented in Yang et al. (2009). For each group of 100 spectra, we stacked the $\log _{10}$ separated source spectra in each consecutive 0.2 amplitude bin and required the minimum number of spectra in each bin to be at least three. We fit the stacked source spectra in a 5 to $30-\mathrm{Hz}$ frequency bandwidth with a Brunetype source model (Brune, 1970; Madariaga, 1976):

$$
u(f)=\frac{\Omega_{0}}{1+\left(f / f_{c}\right)^{n}}
$$

and

$$
f_{c}=\frac{0.42 \beta}{\left(M_{0} / \Delta \sigma\right)^{1 / 3}},
$$

where $n=2$. $\Omega_{0}$ is the source spectrum amplitude at low frequency. $\beta$ is the shear-wave velocity and changes with depth according to a seismic velocity model, SOCAL, which is a general 1D velocity model for the southern California region (Shearer, 1997). Moments were calculated from calibrated magnitudes with the following equation (Kanamori, 1977):

$$
\log _{10} M_{0}=1.5 M+9.1
$$

From source spectra fitting, we removed the common empirical Green's function, which is the stack of all the differences between each source spectrum and theoretical spectrum pair) and obtained the best-fitting stress drop in a wide range, 0.01-100 MPa. (E)We present two examples of the fitting of stress drops with high and low best-fitting stress drops in Figure S1 (available as an electronic supplement to this paper).

\section{Results}

In order to analyze the depth variation in the seismicity patterns, we subdivided the relocated seismicity into six consecutive $3-\mathrm{km}$ depth interval ranges from 0 to $18 \mathrm{~km}$ (Fig. 2). In the shallow depth ranges (0-3, 3-6, and 6-9 km), the spatial distribution of seismicity extends along the Whittier fault, with the majority of events located south of the fault. In the depth range from 9 to $12 \mathrm{~km}$, the distribution of earthquakes becomes more spatially homogeneous across the whole ELA basin. In the deepest depth ranges (12-15 and $15-18 \mathrm{~km}$ ), earthquakes tend to concentrate into a few clusters that are predominantly north of the fault. To ensure that our results are not biased by location method, we compared our relocated catalog with the LSH v.1.12 catalog (Lin et al. 2007) for the ELA basin area. The differences in map location are less than $500 \mathrm{~m}$, and differences in depth are somewhat larger; for example, the location of the Whittier Narrow mainshock and its large aftershocks are in the $15-18 \mathrm{~km}$ depth range in our catalog, and they were in the $12-15 \mathrm{~km}$ depth range in the LSH catalog. This could be caused by different velocity models or different sets of phase picks being used in the two different approaches. We prefer the deeper depths because they are more consistent with previous studies (Hauksson et al., 1988, 2008).

To analyze how the properties of the seismicity change with depth, we determined depth profiles of the magnitude distribution, the $b$ value, and the probability densities of three faulting styles. The magnitude-versus-depth profile in Figure 3 a shows that seven out of eight earthquakes with magnitudes larger than $M 4.5$ occurred at focal depths below $14 \mathrm{~km}$. We calculated $b$ values for events in every 2-km depth interval from 0 to $20 \mathrm{~km}$ (Fig. 3b). To ensure that there are enough samples in each depth bin, we required a minimum number of 30 events in each bin. To account for the catalog completeness, we applied a magnitude cutoff of 1.8 for the $b$-value calculation, which is the level of completeness. The $b$ value was estimated using the maximum likelihood method (Aki, 1965). The standard error of the $b$ value was calculated using the equations derived by Shi and Bolt (1982), which were formulated based on the density distribution of the $b$ value. In general, we found that there is an inverse relationship between $b$ value and the earthquake depth, from 1.3 at shallow depth to 0.6 at the bottom of the seismogenic zone and with an outlier at around $5 \mathrm{~km}$. 


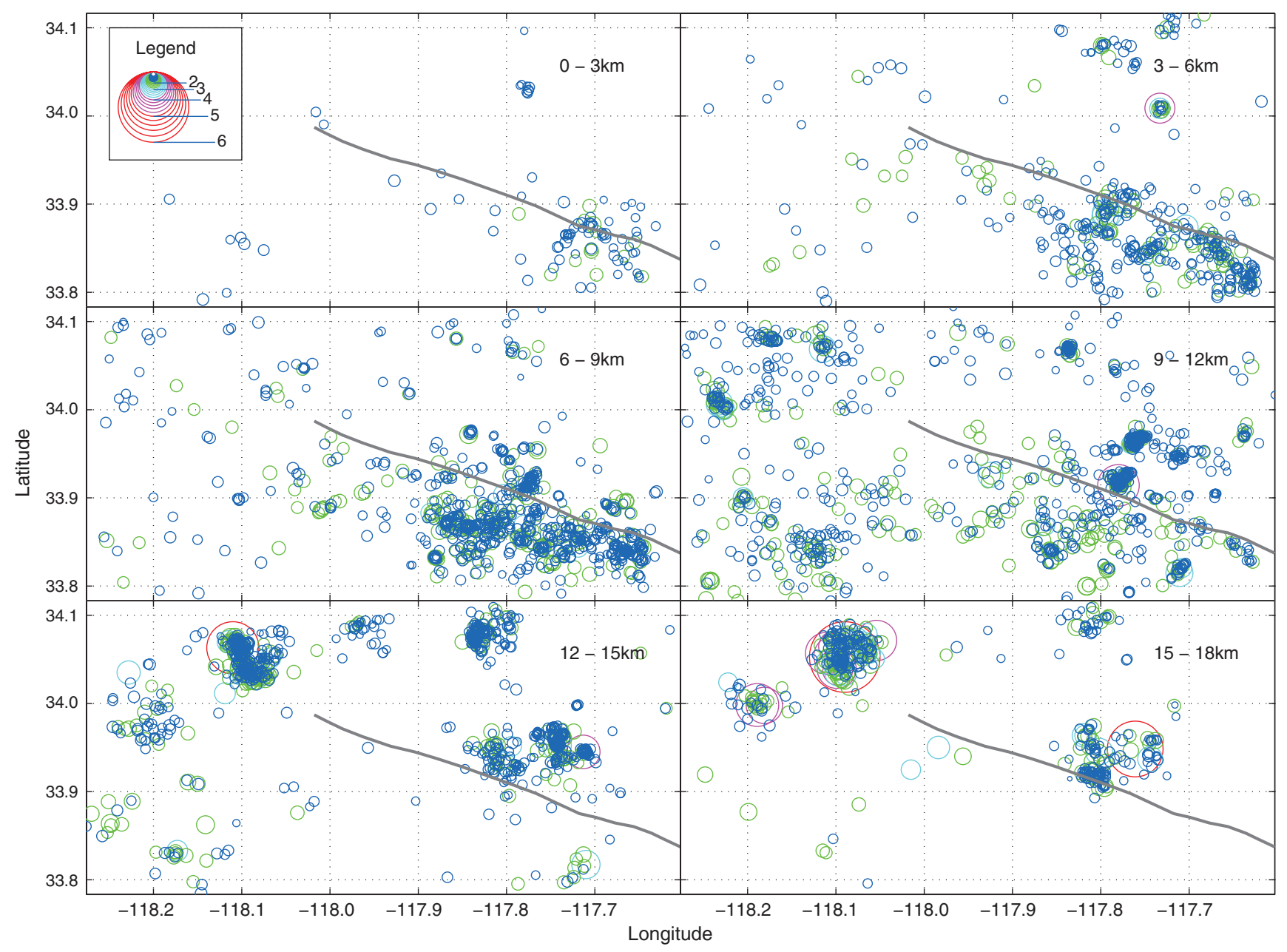

Figure 2. Seismicity patterns of relocated earthquakes in the ELA basin area in each consecutive 3-km depth interval from 0 to $18 \mathrm{~km}$. Depth intervals are indicated at the upper right corner in each panel. As indicated in the legend (top left), earthquake markers are sized and colored by magnitude (smallest circles in blue, $0 \leq M<2$; smaller circles in green, $2 \leq M<3$; circles in cyan, $3 \leq M<4$; large circles in purple, $4 \leq M<5$; largest circles in red, $M \geq 5$ ). The dark curve in each panel marks the surface trace of the Whittier fault.

We determined 2178 focal mechanisms from a data set of 3457 relocated earthquakes. We classified them as strikeslip, reverse, and normal faulting, based on rake angle with a simple $90^{\circ}$ separation rule: Events with rake angles in the $-45^{\circ}$ to $-135^{\circ}$ range are normal faulting; in the $45^{\circ}$ to $135^{\circ}$ range are reverse faulting; and with any other rake angles are strike-slip faulting. Among the 2178 events, $66.1 \%$ of them are strike-slip faulting, $25.2 \%$ of them are reverse faulting, and $8.7 \%$ of them are normal faulting. To determine the variation in faulting with depth, we normalized the numbers of events of each fault type and plotted the three faulting styles as probability density functions (Fig. 3c). At the shallowest depths $(0-6 \mathrm{~km})$, normal faulting has the highest probability density, followed by strike-slip and reverse faulting styles. In the middle depth interval $(6-12 \mathrm{~km})$, the probability density of strike-slip is the highest, and normal faulting is the lowest. In the deepest depth interval $(12-20 \mathrm{~km})$, the reverse faulting has the highest probability density, followed by strike-slip and normal faulting.
We inverted for the 3D stress-field orientation to resolve both spatial and temporal variations. For spatial variations, we divided the mapped area into $5 \times 5 \mathrm{~km}$ squares and the depth range into three consecutive $6 \mathrm{~km}$ interval bins from 0 to $18 \mathrm{~km}$ (Fig. $4 \mathrm{a}-\mathrm{c}$ ). We required a minimum of 10 earthquakes in each cube to be included in our inversion. For temporal variations, we inverted the data in three consecutive decades from 1981 to 2010 and employed the same criteria as used for the spatial domain inversion except for no depth separation (Fig. 5a-c). We selected a damping parameter of 1.2, which is approximately the corner of the trade-off curve between model length and data variance. The orientation distribution of the principal stresses inverted from each cube is plotted on the lower hemisphere stereonet (insert at lower left corner inside each panel in Fig. 4 and Fig. 5). The regional trend of the maximum compressional stress $\left(\sigma_{1}\right)$ systematically changes from north-northwest to north with increasing depth, accompanied by decreasing plunge values. 


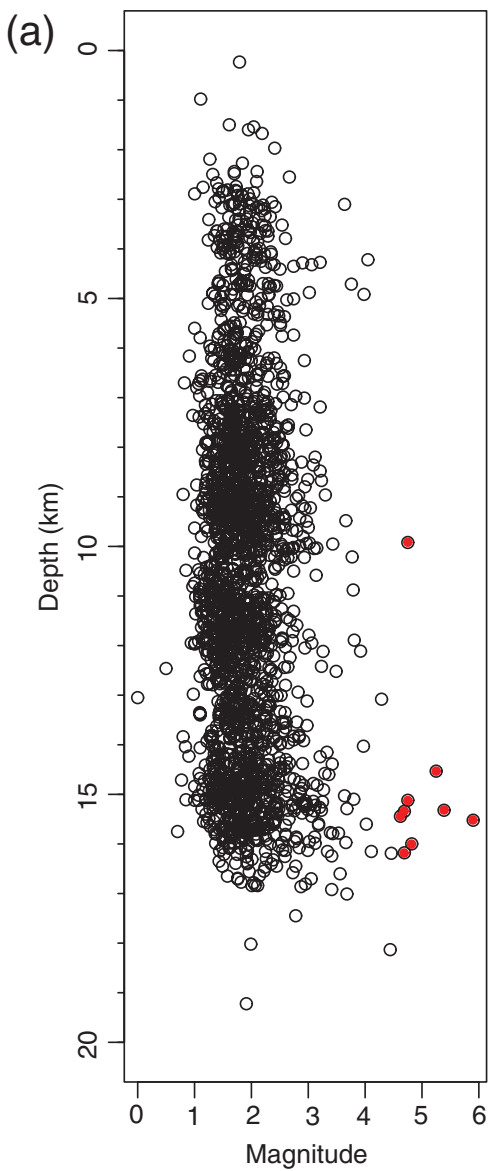

(b)

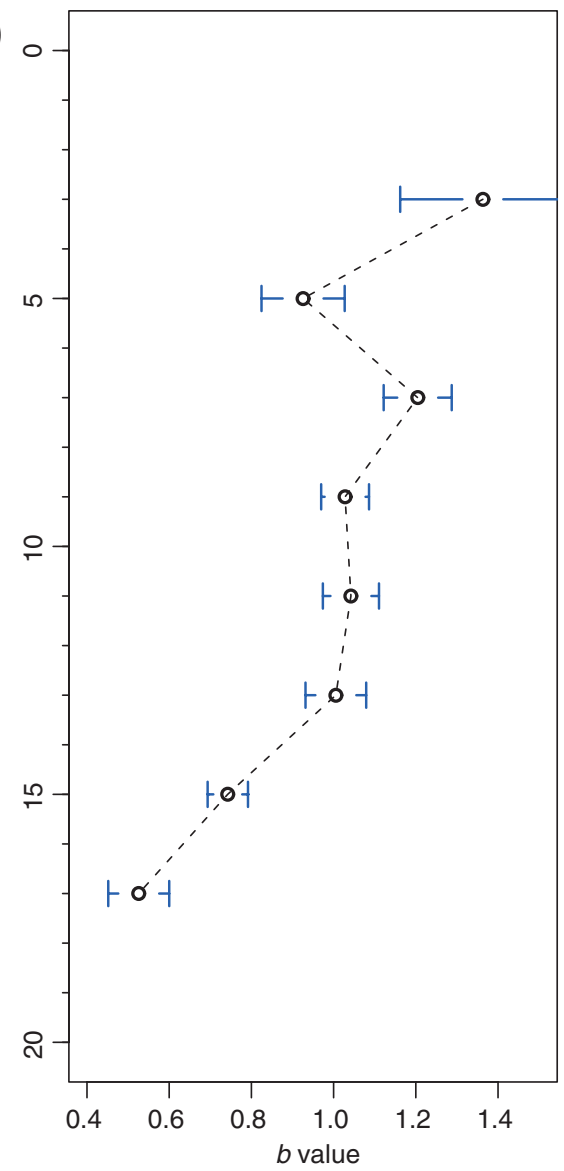

(c)

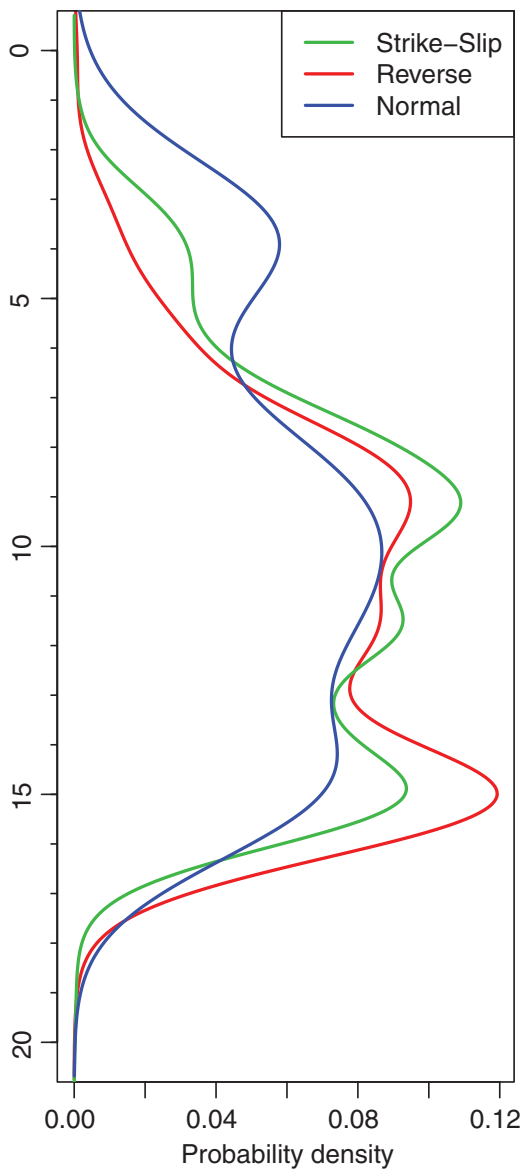

Figure 3. (a) The depth variation of earthquake magnitude, (b) $b$-value, and (c) probability densities of three faulting types. In (a), events with magnitude above 4.5 are colored red.

Compared with spatial variation, the temporal variation of stress-field orientation was smaller. The trend of the $\sigma_{1}$ was nearly north during the 1980s (1122 out of the total 3457 events that occurred in 1981-1990), changed slightly to a north-northwest direction in the 1990s (1140 out of the total 3457 events that occurred in 1991-2000), and continued in the north-northwest direction in the 2000s (1195 out of the total 3457 events that occurred in 2001-2010).

We determined stress drops for 1489 earthquakes using spectral fitting procedures of Yang et al. (2009). To exclude artifacts, we limited the acceptable stress drops to be within 0.01-90 MPa. Approximately 7\% of the events could not be fitted with source spectra, and their best-fitting stress drops fell outside the acceptable range. The spatial distribution of stress drops is shown in Figure 6a, with the calculated stress drops smoothed in each $4.5 \times 4.5 \mathrm{~km}$ square. In Figure 6b, we show the stress-drop distribution along a latitude-depth profile. In Figure $6 c$, we selected data within $10 \mathrm{~km}$ distance of the AB line (green line in Fig. 6a), which is drawn along the Whittier fault, extending northwest to include the hypocenter of the 1987 Whittier Narrows earthquake. We projected the selected data along the $\mathrm{AB}$ line in depth and smoothed the $\log _{10}$ stress drops in each $4.5 \times 4.5 \mathrm{~km}$ square (Fig. 6c). Both depth profiles (Fig. 6b,c) show that stress drop generally increases with depth. The 1D shear-wave velocity model that we used in our calculations is shown in Figure 6d.

In Figure $7 \mathrm{a}$, we have summarized the depth variations in the orientation of the maximum principal stress $\left(\sigma_{1}\right)$. We have calculated the angle between each available $\sigma_{1}$ and north and represented the trend of $\sigma_{1}$ in each 6-km depth range, with positive values on the $x$-axis referring to the east. The mean angle and the corresponding error bars were determined at the average depth of each depth interval (dots in Fig. 7a). The trend of $\sigma_{1}$ rotates from N11.7 $\pm 9.5^{\circ} \mathrm{W}$ at shallow depth $(0-6 \mathrm{~km})$ to $\mathrm{N} 3.0 \pm 12.7^{\circ} \mathrm{W}$ at the intermediate depth $(6-12 \mathrm{~km})$ and to a $\mathrm{N} 0.98 \pm 8.1^{\circ} \mathrm{W}$ at the bottom depth of the seismogenic zone (12-18 km). In Figure 7b, we summarized the temporal variation of the orientation of the $\sigma_{1}$. The mean angle and error bars were placed at the middle year in each decade. The trend of $\sigma_{1}$ rotates from N1.3 \pm $6.8^{\circ} \mathrm{W}$ in $1981-1990$, to $\mathrm{N} 7.4 \pm 9.1^{\circ} \mathrm{W}$ in $1991-2000$, and to $\mathrm{N} 6.9 \pm 8.2^{\circ} \mathrm{W}$ in $2001-2010$.

The stress drop increases with depth, as shown in Figure $7 \mathrm{c}$. We grouped the data into three depth ranges $(0-6,6-12$, and $12-18 \mathrm{~km})$ and calculated the median depths and median $\log _{10}$ stress drops (red squares in Fig. 7c) for 
(a)

(b)

(c)

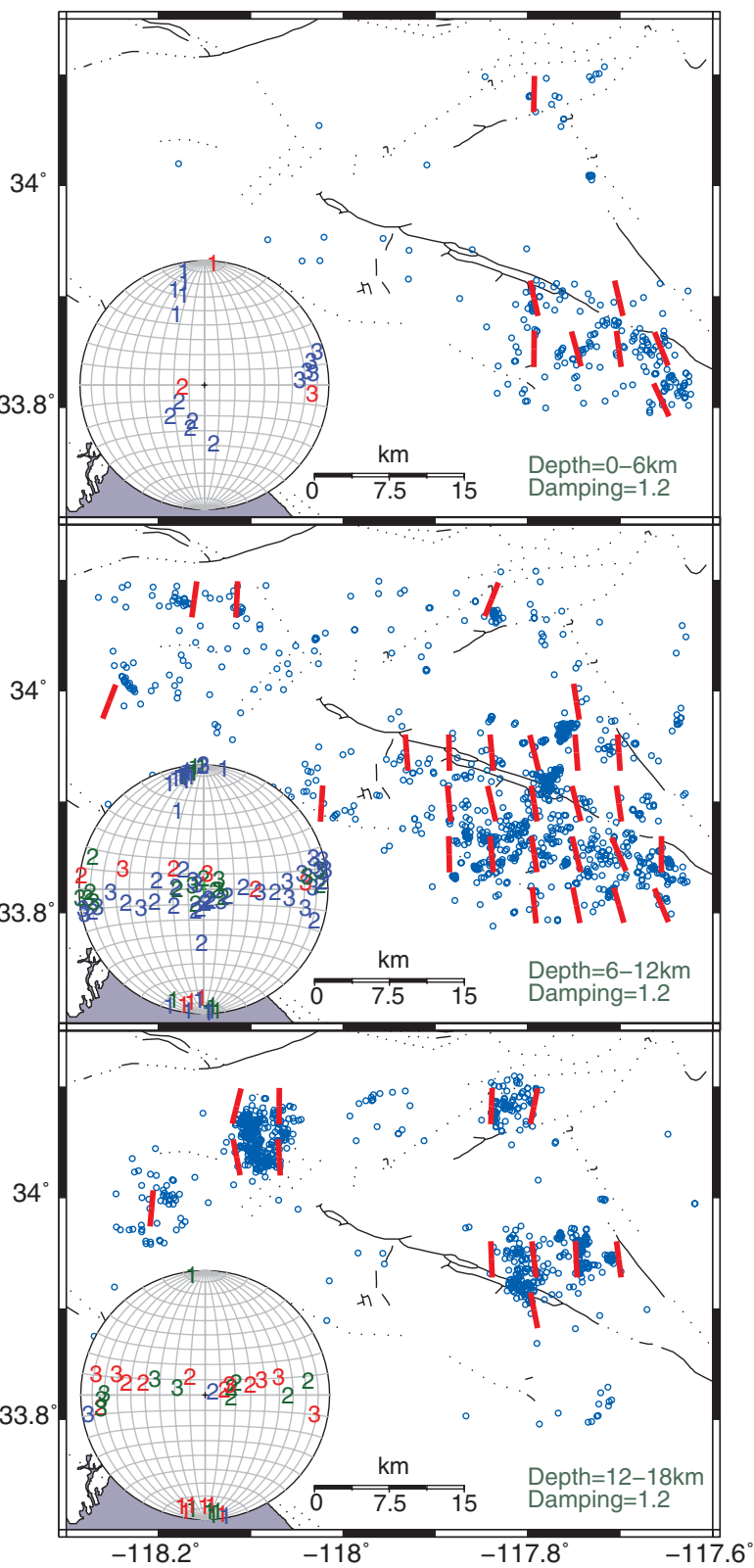

Figure 4. Spatial variation of maximum horizontal stress direction in each consecutive $6 \mathrm{~km}$ depth interval from 0 to $18 \mathrm{~km}$ in the ELA basin area. The blue dots are the available events with focal mechanism solutions. The depth range and damping parameter are marked at the lower right corner in each panel. The stereonet at the lower left corner in each panel shows the spatial distribution of inverted principal stresses: $\sigma_{1}, \sigma_{2}$, and $\sigma_{3}$, which are marked by corresponding stress indexes and colored by latitude (blue, latitude $<33.9^{\circ}$; green, $33.9^{\circ} \leq$ latitude $<34^{\circ}$; red, latitude $\geq 34^{\circ}$ ).

each subset. We fit a straight line to these median points and determined the following empirical stress drop (MPa) and depth $(\mathrm{km})$ relationship from least-square fitting:

$$
\log _{10} \Delta \sigma=0.62+0.065 H \text {. }
$$

Equation 4 shows that the stress drop increases with depth from around $7 \mathrm{MPa}$ at $3 \mathrm{~km}$ to $53 \mathrm{MPa}$ at $17 \mathrm{~km}$ depth in the (a)

(b)

(c)

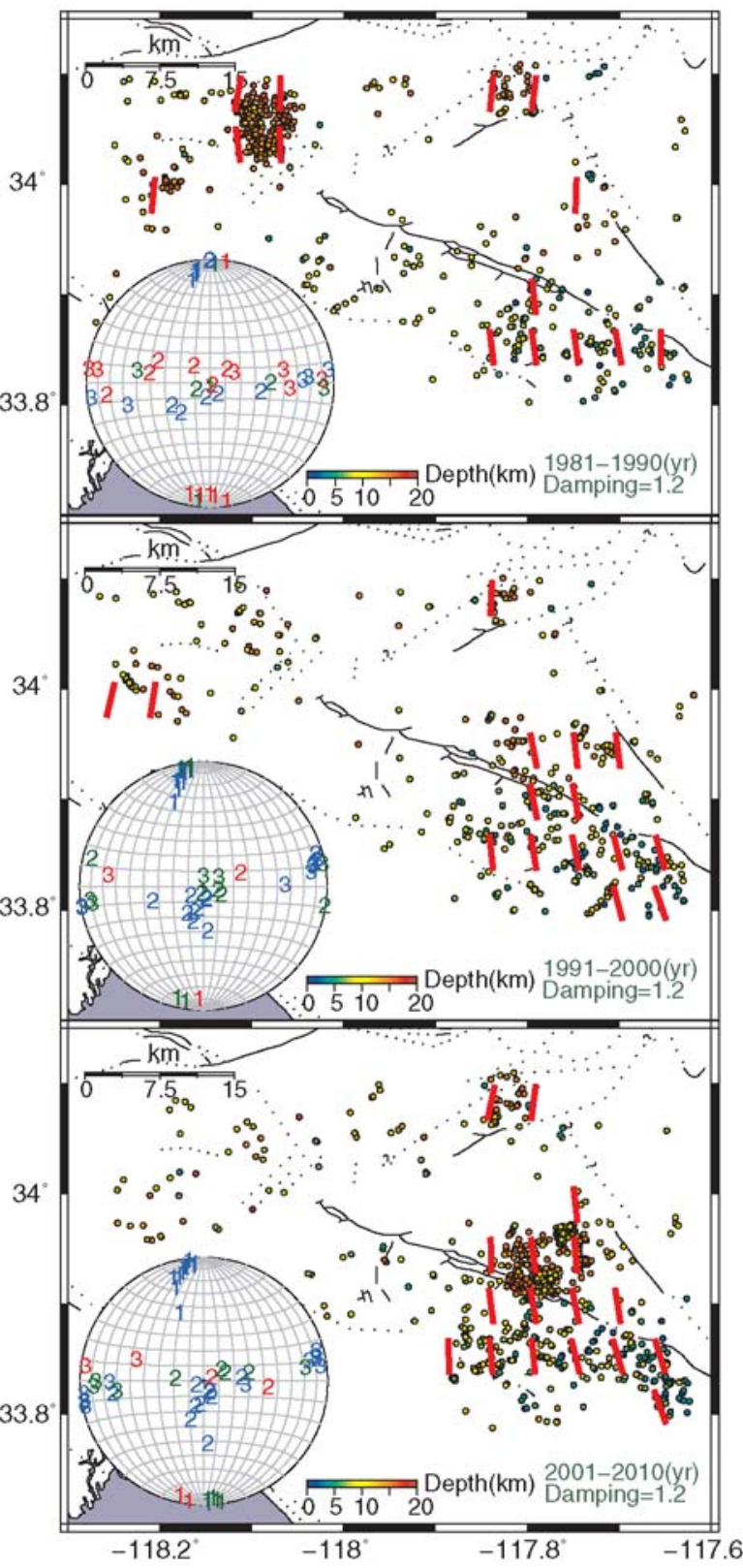

Figure 5. Temporal variations of maximum horizontal stress direction in each consecutive decade from 1981 to 2010. The dots show events in the same decade with focal mechanisms available and are color scaled by depth. The temporal range and damping parameter are marked at the lower right corner in each panel. The stereonet shares the same description as in Figure 4.

ELA basin area, and the data (gray dots in Fig. 7c) scatters \pm 0.5 along the trend in $\log _{10}$ stress-drop scale.

\section{Discussion}

The results of the inversion of groups of focal mechanisms confirm that the direction of the stress field inside the ELA changes with depth. The approximate $11^{\circ}$ angular difference of the maximum compressional stress trends in the shallow and deep parts of the seismogenic zone is associated 

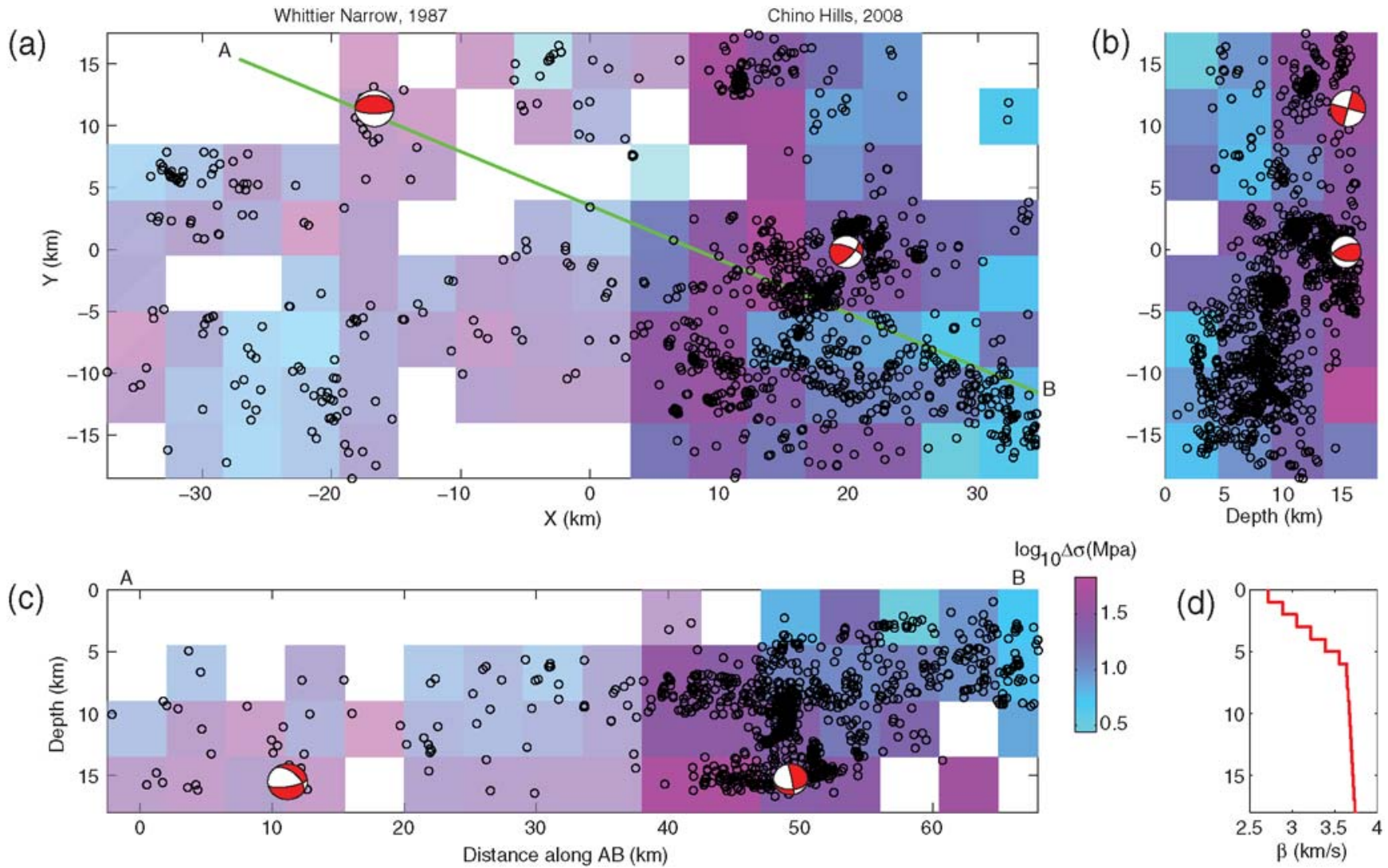

Figure 6. (a) Map view of stress-drop variation in the ELA basin area. Latitude and longitude coordinates are converted to distance relative to a zero point at the center $\left(117.94^{\circ} \mathrm{W}, 33.95^{\circ} \mathrm{N}\right)$ of the ELA basin area (red dashed box in Fig. 1). Stress drops are smoothed in each $4.5 \times 4.5 \mathrm{~km}$ grid and colored by $\log _{10}$ stress drop (legend at the lower right). Events used in stress-drop calculations are marked in black circles. Focal mechanisms of the Whittier Narrows earthquake and the Chino Hills earthquake are shown. The green AB line is drawn along the Whittier fault and extends to cover the Whittier Narrows epicenter. (b) The projection of (a) in the latitude-depth profile. (c) Events in (a) within $10 \mathrm{~km}$ distance of the $\mathrm{AB}$ line are selected and projected along the AB-depth profile. White colored grids in (a) and (c) have insufficient data and larger fitting errors. (d) The employed 1D shear-wave velocity model.

with regional tectonics and is likely caused by movement along two types of fault systems: the Whittier fault and other strike-slip faults and the blind Puente Hills Thrust (PHT) fault system. The Whittier fault is a right-lateral strike-slip fault, with its southern terminus at the north end of the Elsinore fault, which is a major fault striking subparallel to the San Andreas fault (SAF). Two left-lateral strike-slip faults, the San Jose and Raymond faults (Fig. 1) accommodate westward translation of crustal blocks and support the eastwest escape tectonics model in the Los Angeles metropolitan region (Walls et al., 1998). The terms "escape tectonics" and "extrusion tectonics" from Tapponnier et al. (1982) refer to the movement on strike-slip faults resulting from plate collision. The PHT system is associated with regional north-south compression, and its general depth range is from 5 to $15 \mathrm{~km}$, based on seismic reflection surveys (Shaw and Shearer, 1999).

In the depth range between 0 and $9 \mathrm{~km}$, the seismicity is controlled by the Whittier fault and east-west escape tectonics, with the strike of seismicity alignments commonly in a northwest-west direction and some percentage of normal faulting. We speculate that the two fault systems couple in the depth range between 9 and $12 \mathrm{~km}$, where all three faulting styles coexist, and earthquakes are distributed evenly over the whole area. This zone appears to exhibit complex shearing over a broad depth interval rather than being a well-developed narrow shallow crustal decollement. The bottom of the seismogenic zone in depths between 12 and $18 \mathrm{~km}$ is generally controlled by the PHT fault system, with earthquakes concentrated into a few north-south strike clusters where reverse faulting dominates. This suggests the presence of thrust ramps. As the lower crust moves northward, underthrusting beneath the San Gabriel Mountains, it may load the thrust ramps with additional stress to accommodate the more westerly striking SAF system as compared to the northwestward plate motion.

The magnitude-depth relationship shows that moderate to larger earthquakes are more likely to nucleate near the base of the seismogenic zone in the ELA basin area, which is consistent with previous studies (Sibson, 1982; Das and Scholz, 1983). One of the statistical parameters that depicts the properties of regional seismicity is the $b$ value in the 
(a)

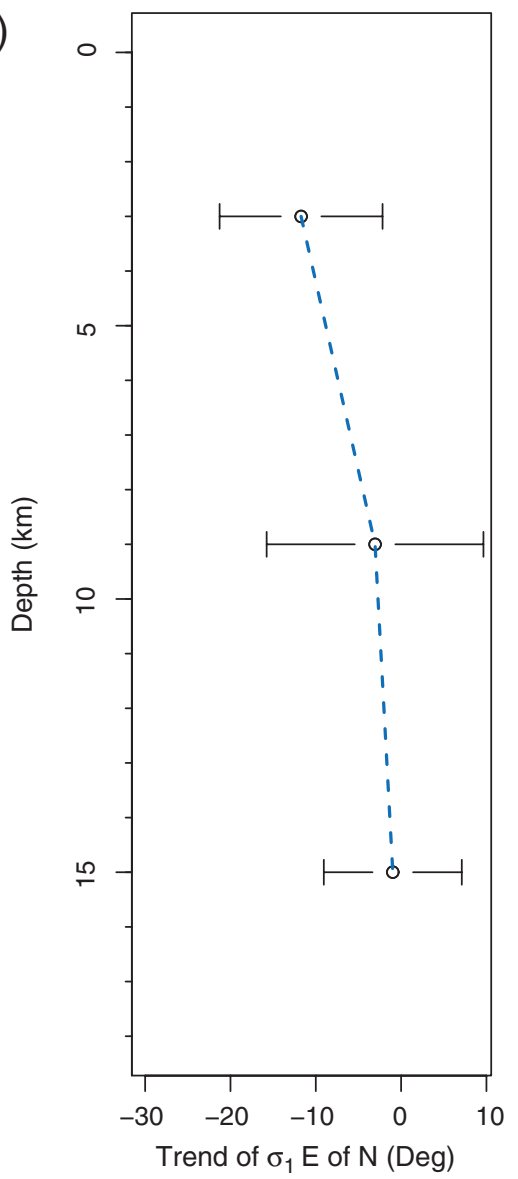

(b)

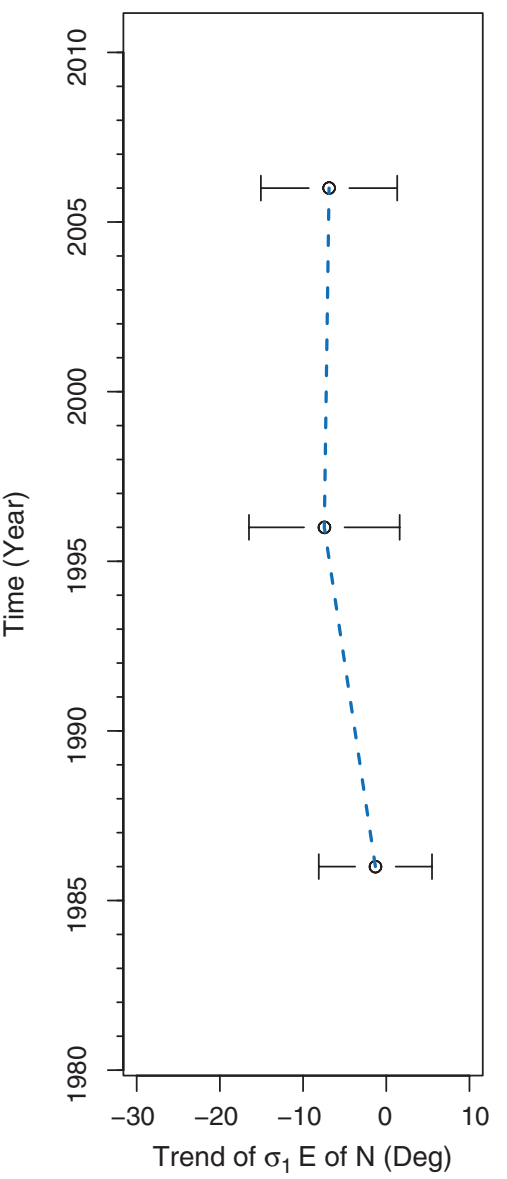

(c)

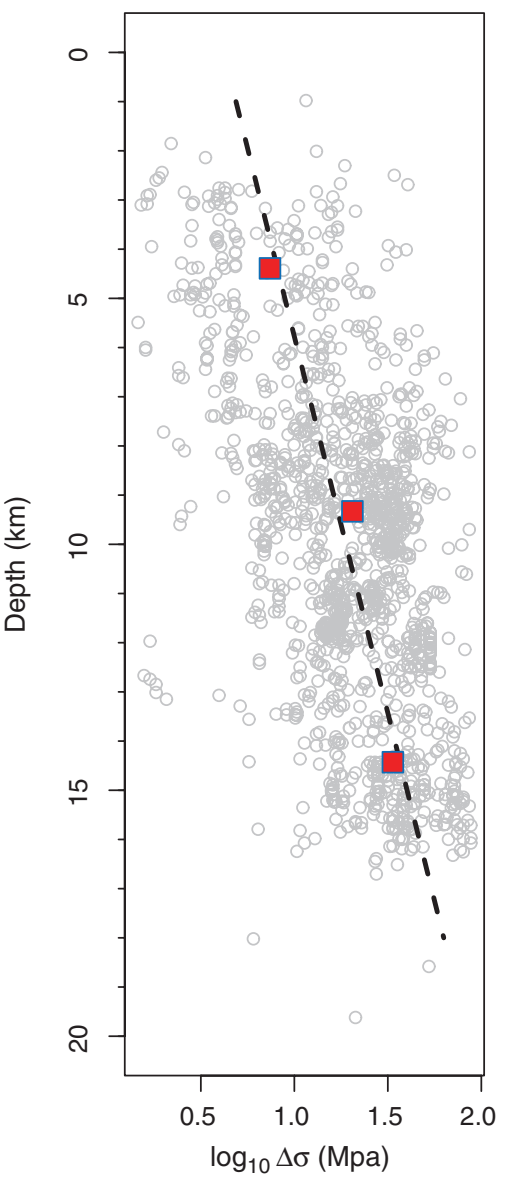

Figure 7. (a) The trend of the maximum horizontal stress orientations for three depth ranges. The error bar represents the one-sigma standard deviation determined from available data in each depth range. (b) The trend of the maximum horizontal stress orientations for three decades. The error bar represents the one-sigma standard deviation. (c) The variation of $\log _{10}$ stress drops (gray dots) with depth. The red squares are the median $\log _{10}$ stress drops at median depth in each 6-km depth range, and all of them are fitted by the least-square method (dashed line). (E, east; N, north.)

Gutenberg-Richter relationship (Gutenberg and Richter, 1944). The variation of $b$ value could be associated with stress conditions (Scholz, 1968) and degree of material heterogeneity (Mogi, 1962). In our study, similar to Mori and Abercrombie (1997), we obtained a negative relationship between the $b$ value and depth, which suggests that the stress conditions at increasing depth favors the nucleation of larger events instead of smaller ones. The stress-drop inversion shows that the $\log _{10}$ stress drop increases with depth, consistent with the patterns reported by Hardebeck and Hauksson (2001), Shearer et al. (2006) in the southern California region and by Yang et al. (2009) in the 1999 İzmit-Düzce aftershock zone in Turkey. Our results also agree with Schorlemmer et al. (2005) that the $b$ value could be used as a stress meter and that the decrease of $b$ value with depth implied an increase in differential stress.

Using the 30-year seismicity catalog, we also identified temporal variations in the stress-field orientation at the selected depth intervals. In a previous study, Press and Allen (1995) classified the southern California earthquakes into San Andreas (SA) and non-San Andreas (NSA) types and found that only one type of event predominates in a time epoch. During the period from 1981 to 1990, the stress-field orientation in the ELA basin was in a nearly north direction, which indicated that the stress field close to the bottom of the seismogenic zone was relatively active, accompanied by the occurrence of the 1987 Whittier Narrows M 5.9 earthquake sequence and the 1989 Montebello $M 4.8$ earthquake sequences (Hauksson, 1990). The stress-field orientation in the ELA basin rotated about $7^{\circ}$ from north to the northwest in the 1990s and kept the same in the 2000s, which matched with the SA type. With the limited temporal span, we do not know when this SA-type epoch will end; however, the occurrence of the 2008 Chino Hills $M_{\mathrm{w}} 5.4$ earthquake sequence and the recent 2010 Pico Rivera $M_{\mathrm{w}} 4.4$ isolated deep earthquake (19 km; Hauksson et al., 2008) could indicate the NSA-type earthquakes may become more frequent.

The stress drop is relatively high along the Whittier fault, and to the west of the Chino Hills hypocenter at around $15 \mathrm{~km}$ depth (Fig. 6c). Areas with relatively high stress drop could favor the occurrence of larger earthquakes. For example, the triggered 1999 Düzce $M 7.1$ mainshock occurred in a 
region with high-stress-drop events along the North Anatolia fault (Yang et al., 2009). Thus, part of the Whittier fault to the northwest of the Chino Hills 2008 earthquake hypocenter could be a potential source area for future moderate-to-large earthquake in the ELA basin.

Recent studies have shown that low-frequency events are associated with the down-dip edge in megathrust zones, such as in the Cascadian subduction zone (Rogers and Dragert, 2003) and the base of the seismogenic zone along the SAF in central California (Nadeau and Dolenc, 2004). With more sensitive instruments, possible beam-forming array techniques, and borehole observations, we might be able to detect such phenomena associated with slow slip along decollement beneath the ELA basin, and this could contribute to understanding how the shallow and deep tectonic regimes interact.

Based on the depth variations in stress drop, maximum compressional stress orientation, seismicity relationships, and previous work using geological and seismic refraction and reflection surveys in the ELA basin area (Fuis et al.,
2001; Bjorklund and Burke, 2002; Shaw et al., 2002), we have assembled a 3D seismotectonic model as illustrated in Figure 8. The top of the model shows a map view of the ELA basin. In the front side of the model, the red arrows represent the orientation of maximum horizontal stress at shallow depth and at the bottom of the seismogenic zone in the ELA area. The relative low $b$ value at around $5-\mathrm{km}$ depth could be associated with the presence of the PHT fault in the same depth range. The right side of the model shows the Puente Hills anticline fold (Bjorklund and Burke, 2002), together with the Whittier fault and faults of the Puente Hills blind-thrust fault system, stress drops, and earthquakes in latitude-depth profile. The dashed lines at the bottom of the model represent regional decollement with the lower crust below it.

The low-angle aftershock planes (defined by aftershocks that occurred in the first three days) for both the Whittier Narrows and the Chino Hills earthquakes (Hauksson et al., 2008), together with overall deepest earthquakes distribution in the ELA basin area, suggest that the bottom of

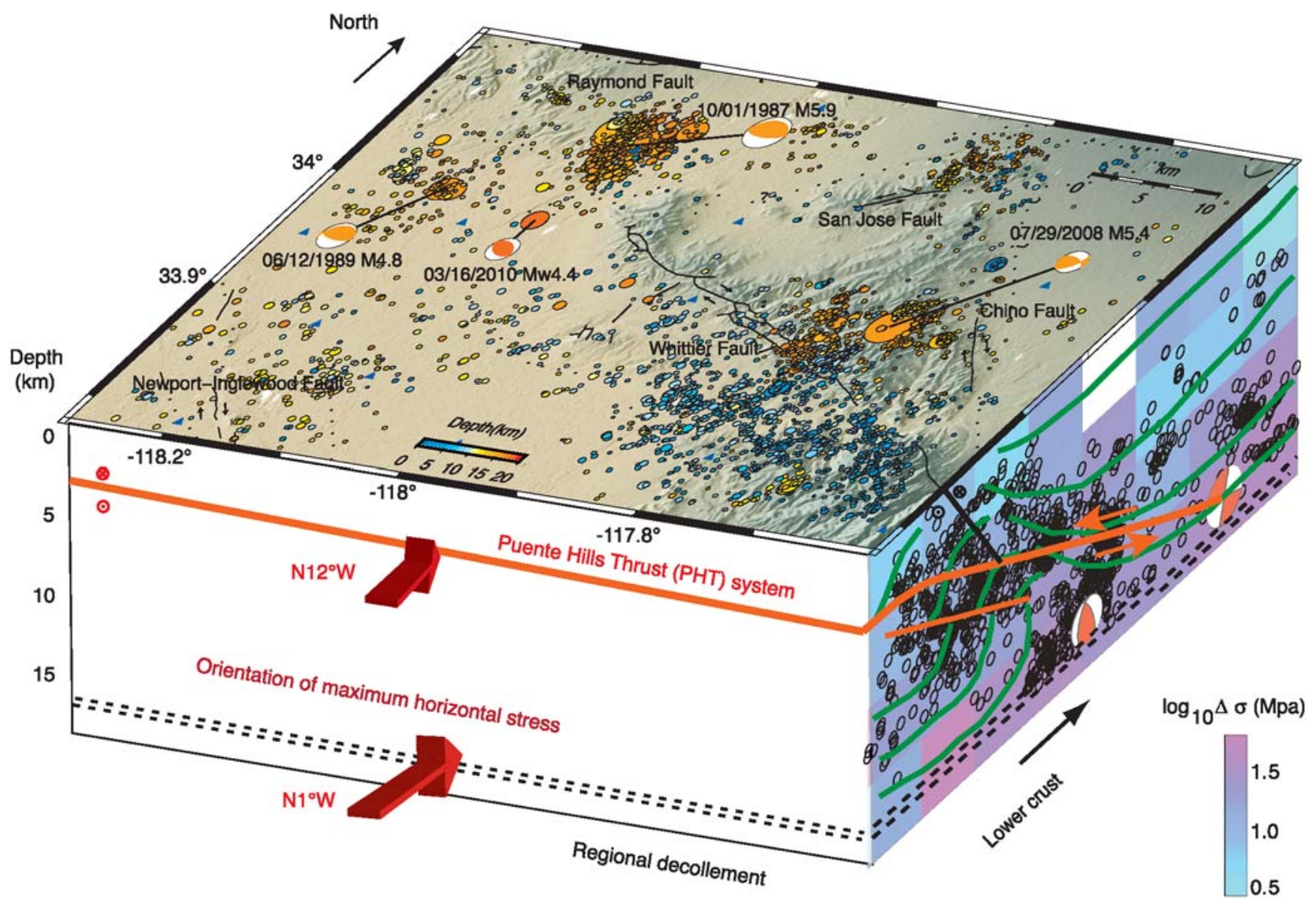

Figure 8. A comprehensive model of the seismotectonics of the ELA basin area. The top of the 3D block is the topographic map view of the ELA basin area (rectangle in Fig. 1). On the front face of the 3D block, red arrows mark the maximum horizontal stress orientation at shallow and midcrustal depths. The right face is the projection of Figure 6b, with the addition of the Puente Hills anticline fold (Bjorklund and Burke, 2002; green curves), the Whittier fault (black line), and the faults of the Puente Hills blind-thrust system (orange lines). The PHT system is also marked on the front face. Fault locations are from Plesch et al. (2007). The dashed parallel lines near the base correspond to the regional decollement, which separates the upper and lower crusts. 
the seismogenic zone is almost flat, which is consistent with a regional horizontal decollement separating the upper brittle crust from the lower ductile crust (Hadley and Kanamori, 1978; Webb and Kanamori, 1985; Huang et al., 1996). At depth below the decollement, the ductile lower crust drags the upper crust northward to underthrusting below the San Gabriel Mountains, and the deeper seismicity and the existence of the Puente Hills blind-thrust fault system and the Puente Hills anticline fold are the corresponding tectonic features in the upper crust. Furthermore, Sonder (1990) suggested that the variation of the maximum principal stresses direction observed in the Transverse Ranges of central California could be explained by density anomaly, and seismic evidence (Humphreys et al., 1984) showed that a wedgeshaped high-density region exists underneath the Transverse Ranges in the upper mantle.

We infer that the pure strike-slip motion along the Elsinore fault to the south is partitioned onto the more westerly striking Whittier fault and east-west striking and northdipping blind-thrust ramps at depth. These blind thrusts may sole out in a decollement at $\sim 20 \mathrm{~km}$ depth. Large earthquakes can occur both on the Whittier fault and on the blindthrust ramps. However, the spatial patterns of stress drop suggest that the deep-thrust faulting earthquakes have higher stress drops and thus can radiate more high frequencies, potentially causing more damage than the shallow strike-slip events.

\section{Conclusions}

Vertical partitioning of northwest-striking strike-slip tectonic motion and oblique-to-pure compressional motion exists beneath the east Los Angles basin. Strike-slip motion with a small component of normal motion characterizes the upper crust in the depth range of 0-9 km, with the seismicity being distributed along the Whittier fault. A transition zone in the depth range of 9-12 km exhibits diffuse distribution of background seismicity and mixed styles of faulting. Below $12 \mathrm{~km}$, moderately dipping oblique-slip to pure compressional-slip tectonics dominate, with seismicity concentrating into few clusters striking north.

The calculated $b$ value generally decreases with depth from 1.1 at shallow depth to 0.8 at the bottom of the seismogenic zone, with an outlier at around $5 \mathrm{~km}$.

Evidence from the stress-field orientation inversion show that the direction of maximum compressional stress rotates from $\mathrm{N} 12^{\circ} \mathrm{W}$ at shallow depth to $\mathrm{N} 1^{\circ} \mathrm{W}$ at the bottom of the seismogenic zone in the ELA basin area. In comparison, the temporal variation of stress field is relative small over the past 30 years, with only about $6^{\circ}$ rotation westward from the north direction since the 1980s.

Stress drops inverted from $P$ waves increase with depth from around $7 \mathrm{MPa}$ at shallow depth to around $53 \mathrm{MPa}$ at the base of the seismogenic zone.

These conclusions are consistent with existing geological models and provide additional evidence for the vertical partitioning of styles of deformation and state of stress in the ELA basin area.

\section{Data and Resources}

The earthquake data used in this study were recorded by the Caltech/U.S. Geological Survey (USGS) Southern California Seismic Network (SCSN) and were made available by the Southern California Earthquake Data Center (SCEDC). The data were obtained from http://www.data.scec.org; and information about the network was from http://www .scsn.org. Most figures were done using Generic Mapping Tools (Wessel and Smith, 1991). The hypoDD, HASH, and SATSI programs were downloaded from the USGS (http:// earthquake.usgs.gov/research/software). The LSH v.1.12 catalog was downloaded from http://www.data.scec.org/ research/altcatalogs.html (last accessed October 2010).

\section{Acknowledgments}

This research was supported by U.S. Geological Survey Grant G10AP00017 and by the Southern California Earthquake Center (SCEC). SCEC is funded by National Science Foundation Cooperative Agreement EAR-0529922 and USGS Cooperative Agreement 07HQAG0008. This article is SCEC contribution number 1444 and contribution number 10053 of the Seismological Laboratory, Division of Geological and Planetary Sciences, California Institute of Technology, Pasadena. We gratefully acknowledge the Southern California Earthquake Data Center for providing the data set, Jeanne Hardebeck for providing the HASH and the SATSI programs and useful discussions, and Debi Kilb, Joann Stock, Iain Bailey, Peter Shearer, and Robert Yeats for valuable comments. We are grateful to the operators and analysts who maintain the USGS/Caltech Southern California Seismic Network and who pick and archive the seismograms.

\section{References}

Aki, K. (1965). Maximum likelihood estimate of $b$ in the formula $\log N=$ $a-b M$ and its confidence limits, Bull. Earthq. Res. Inst. 43, 237-239. Angelier, J. (1984). Tectonic analysis of fault slip data sets, J. Geophys. Res. 89, 5835-5848.

Bjorklund, T., and K. Burke (2002). Four-dimensional analysis of the inversion of a half-graben to form the Whittier fold-fault system of the Los Angeles basin, J. Struct. Geol. 24, 1369-1397.

Brune, J. N. (1970). Tectonic stress and the spectra of seismic shear waves from earthquakes, J. Geophys. Res. 75, 4997-5009.

Das, S., and C. H. Scholz (1983). Why large earthquakes do not nucleate at shallow depths, Nature 305, 621-623.

Fuis, G. S., T. Ryberg, N. J. Godfrey, D. A. Okaya, and J. M. Murphy (2001). Crustal structure and tectonics from the Los Angeles basin to the Mojave Desert, southern California, Geology 29, 15-18.

Gephart, J. W., and D. W. Forsyth (1984). An improved method for determining the regional stress tensor using earthquake focal mechanism data: Application to the San Fernando earthquake sequence, J. Geophys. Res. 89, 9305-9320.

Gutenberg, B., and C. F. Richter (1944). Frequency of earthquakes in California, Bull. Seismol. Soc. Am. 34, 185-188.

Hadley, D., and H. Kanamori (1978). Recent seismicity in the San Fernando region and tectonics in the west-central Transverse Ranges, California, Bull. Seismol. Soc. Am. 68, 1449-1457.

Hardebeck, J. L., and E. Hauksson (2001). Crustal stress field in southern California and its implications for fault mechanics, J. Geophys. Res. 106, 21,859-21,882. 
Hardebeck, J. L., and A. J. Michael (2006). Damped regional-scale stress inversions: Methodology and examples for southern California and the Coalinga aftershock sequence, J. Geophys. Res. 111, no. B11310, doi 10.1029/2005JB004144.

Hardebeck, J. L., and P. M. Shearer (2002). A new method for determining first-motion focal mechanisms, Bull. Seismol. Soc. Am. 92, 22642276.

Hardebeck, J. L., and P. M. Shearer (2003). Using $S / P$ amplitude ratios to constrain the focal mechanisms of small earthquakes, Bull. Seismol. Soc. Am. 93, 2434-2444.

Hauksson, E. (1990). Earthquakes, faulting, and stress in the Los Angeles basin, J. Geophys. Res. 95, 15365-15394.

Hauksson, E. (2000). Crustal structure and seismicity distribution adjacent to the Pacific and North America plate boundary in southern California, J. Geophys. Res. 105, 13,875-13,903.

Hauksson, E., and L. Jones (1989). The 1987 Whittier Narrows earthquake sequence in Los Angeles, southern California: Seismological and tectonic analysis, J. Geophys. Res. 94, 9569-9589.

Hauksson, E., K. Felzer, D. Given, M. Giveon, S. Hough, K. Hutton, H. Kanamori, V. Sevilgen, S. Wei, and A. Yong (2008). Preliminary report on the 29 July $2008 M_{\mathrm{w}} 5.4$ Chino Hills, eastern Los Angeles basin, California, earthquake sequence, Seism. Res. Lett. 79, 855-866.

Hauksson, E., L. M. Jones, T. L. Davis, K. L. Hutton, P. Williams, A. L. Bent, G. Brady, P. A. Reasenberg, A. J. Michael, R. F. Yerkes, E. Etheredge, R. L. Porcella, M. J. S. Johnston, G. Reagor, C. W. Stover, C. G. Bufe, E. Cranswick, and A. K. Shakal (1988). The 1987 Whittier Narrows earthquake in the Los Angeles metropolitan area, California, Science 239, 1409-1412.

Huang, W., L. T. Silver, and H. Kanamori (1996). Evidence for possible horizontal faulting in southern California from earthquake, Geology 24, 123-126.

Humphreys, E., R. W. Clayton, and B. H. Hager (1984). A tomographic image of mantle structure beneath Southern California, Geophys. Res. Letters 11, 625-627.

Hutton, K., J. Woessner, and E. Hauksson (2010). Earthquake monitoring in southern California for seventy-seven years (1932-2008), Bull. Seismol. Soc. Am. 100, 423-446.

Kanamori, H. (1977). The energy release in great earthquakes, J. Geophys. Res. 82, 2981-2987.

Lin, G., P. Shearer, and E. Hauksson (2007). Applying a three-dimensional velocity model, waveform cross correlation, and cluster analysis to locate southern California seismicity from 1981 to 2005, J. Geophys. Res. 112, no. B12309, doi 10.1029/2007JB004986.

Madariaga, R. (1976). Dynamics of an expanding circular fault, Bull. Seismol. Soc. Am. 66, 639-666.

Michael, A. J. (1984). Determination of stress from slip data: Faults and folds, J. Geophys. Res. 89, 11,517-11,526.

Mogi, K. (1962). Magnitude-frequency relation for elastic shocks accompanying fractures of various materials and some related problems in earthquakes, Bull. Earthq. Res. Inst. 40, 831-853.

Mori, J., and R. E. Abercrombie (1997). Depth dependence of earthquake frequency-magnitude distributions in California: Implications for rupture initiation, J. Geophys. Res. 102, no. B7, 15,081-15,090.

Nadeau, R. M., and D. Dolenc (2004). Nonvolcanic tremors deep beneath the San Andreas fault, Science 307, 389.

Park, J., C. R. Lindberg, and F. L. Vernon (1987). Multitaper spectral analysis of high frequency seismograms, J. Geophys. Res. 92, $12,675-12,648$.

Plesch, A., J. H. Shaw, C. Benson, W. A. Bryant, S. Carena, M. Cooke, J. Dolan, G. Fuis, E. Gath, L. Grant, E. Hauksson, T. H. Jordan, M. Kamerling, M. Legg, S. Lindvall, H. Magistrale, C. Nicholson, N. Niemi, M. Oskin, S. Perry, G. Planansky, T. Rockwell, P. Shearer, C. Sorlien, M. P. Süss, J. Suppe, J. Treiman, and R. Yeats (2007).
Community fault model (CFM) for southern California, Bull. Seismol. Soc. Am. 97, 1793-1802.

Press, F., and C. Allen (1995). Patterns of seismic release in the southern California region, J. Geophys. Res. 100, 6421-6430.

Rogers, G., and H. Dragert (2003). Episodic tremor and slip on the Cascadia subduction zone: The chatter of silent slip, Science 300, 1942-1943.

Scholz, C. H. (1968). Mircrofractures, aftershocks, and seismicity, Bull. Seismol. Soc. Am. 58, 1117-1130.

Schorlemmer, D., S. Wiemer, and W. Max (2005). Variations in earthquakesize distribution across different stress regimes, Nature 437, 539-542.

Shaw, J. H., and P. M. Shearer (1999). An elusive blind-thrust fault beneath metropolitan Los Angeles, Science 283, 1516-1518.

Shaw, J., A. Plesch, J. Dolan, T. Pratt, and P. Fiore (2002). Puente Hills blind-thrust system, Los Angeles, California, Bull. Seismol. Soc. Am. 92, 2946.

Shearer, P. M. (1997). Improving local earthquake locations using the L1 norm and waveform cross-correlation: application to the Whittier Narrows, California, aftershock sequence, J. Geophys. Res. 102, 8269-8283.

Shearer, P. M., G. A. Prieto, and E. Hauksson (2006). Comprehensive analysis of earthquake source spectra in southern California, J. Geophys. Res. 111, no. B06303, doi 10.1029/2005JB003979.

Shi, Y., and B. A. Bolt (1982). The standard error of the magnitudefrequency $b$ value, Bull. Seismol. Soc. Am. 72, 1677-1687.

Sibson, R. (1982). Fault zone models, heat flow, and the depth distribution of earthquakes in the continental crust of the United States, Bull. Seismol. Soc. Am. 72, 151-163.

Sonder, L. (1990). Effects of density contrasts on the orientation of stresses in the lithosphere: Relation to principal stress directions in the Transverse Ranges, California, Tectonics 9, 761-771.

Tapponnier, P., G. Peltzer, A. Y. L. Dain, and R. Armijo (1982). Propagating extrusion tectonics in Asia: New insights from simple experiments with plasticine, Geology 10, 611-616.

Thomson, D. J. (1982). Spectrum estimation and harmonic analysis, Proc. IEEE. 70, 1055-1096.

Thurber, C. H. (1993). Local earthquake tomography: Velocities and $V_{P} / V_{S}$ theory, in Seismic Tomography: Theory and Practice, H. M. Iyer and K. Hirahara (Editors), Chapman and Hall, London, 563-583.

Waldhauser, F., and W. L. Ellsworth (2000). A double-difference earthquake location algorithm: Method and application to the northern Hayward fault, Bull. Seismol. Soc. Am. 90, 1353-1368.

Walls, C., T. Rockwell, K. Mueller, Y. Bock, S. Williams, J. Pfanner, J. Dolan, and P. Fang (1998). Escape tectonics in the Los Angeles metropolitan region and implications for seismic risk, Nature 394, 356-360.

Webb, T., and H. Kanamori (1985). Earthquake focal mechanisms in the eastern Transverse Ranges and San Emigdio Mountains, southern California and evidence for a regional decollement, Bull. Seismol. Soc. Am. 75, 737-757.

Wessel, P., and W. H. F. Smith (1991). Free software helps map and display data, Eos Trans. AGU, 72, 441, 445-446.

Yang, W., Z. Peng, and Y. Ben-Zion (2009). Variations of strain drops in aftershocks of the 1999 Izmit and Düzce earthquakes along the Karadere-Düzce branch of the North Anatolian fault, Geophys. J. Int. 177, 235-246.

Seismological Laboratory

California Institute of Technology

1200 E. California Blvd.

Mail Code 252-21

Pasadena, California 91125

Manuscript received 9 August 2010 